\title{
Do Ut pictura poesis à narrativa de Clarice Lispector
}

From Ut pictura poesis to the narrative of Clarice Lispector

Joelma Santana Siqueira

Universidade Federal de Viçosa, Viçosa, MG, Brasil

Resumo: Este trabalho recupera a discussão sobre o Ut pictura poesis, focaliza a comparação entre literatura e pintura modernas e propõe relação com os textos "Romance" e “Escrever, humildade, técnica", de Clarice Lispector, publicados na primeira edição da obra A legião estrangeira (1964).

Palavras-chave: Ut pictura poesis. Literatura e pintura. Narrativa moderna. Pintura moderna. Clarice Lispector.

Abstract: The work follows the discussion on Ut pictura poesis, it focuses on the comparison between modern literature and painting and proposes a relationship with texts by Clarice Lispector, "Romance" and "Escrever, Humildade, Técnica", published in the first edition of the book A Legião Estrangeira (1964).

Keywords: Ut pictura poesis. Literature and painting. Modern narrative. Modern Painting. Clarice Lispector.

No texto "O paralelo das artes", Jacqueline Lichtenstein (2005, p. 9-10) destacou que, a partir do Renascimento, a maioria das pessoas que escreve sobre pintura dedica-se à comparação entre as artes de duas maneiras: uma mais genérica, aproximando as artes conforme estas se relacionam ao sentido da visão ou ao sentido da audição, inserida em uma longa tradição que, "segundo Platão, remontaria a Simônides de Ceos, e que nos foi transmitida através da formulação feita por Horácio, no século I, em sua Epístola aos Pisãos" e tomou a forma de uma comparação entre a pintura e a poesia - "Ut pictura poesis", "um poema é como um quadro"; e outra, restrita às relações entre a pintura e a escultura, que diz respeito ao problema do paragone, primeiramente formulado, nos termos novos do humanismo, por Leon Battista Alberti. 
Joelma Santana

Siqueira

168

Lichtenstein considera que, embora diferentes em muitos pontos, as duas comparações estão relacionadas, pois “o paragone só adquire verdadeiramente sentido no interior da problemática geral do Ut pictura poesis na medida em que a condição atribuída à pintura, em relação à poesia, determina a condição atribuída à escultura, em relação à pintura" (LICHTENSTEIN, 2005, p. 11). Ao ter comparado a poesia à pintura, fazendo desta última o termo referencial da comparação, Horácio criou "um privilégio em favor das artes da imagem, com as quais são relacionadas as artes da linguagem". Os teóricos do Renascimento inverteram o sentido da frase para "a pintura é como a poesia, o quadro é como um poema" (LICHTENSTEIN, 2005, p. 11). Longe de um simples erro de tradução, a inversão "foi um dos meios - e certamente um dos mais importantes - que iria permitir à pintura gozar de um reconhecimento até então reservado às artes da linguagem" (LICHTENSTEIN, 2005, p. 11).

O Ut pictura poesis funcionou como "a peça essencial de um imenso empreendimento de legitimação social e teórica da pintura" (LICHTENSTEIN, 2005, p. 12), atividade anteriormente denunciada por Platão como prática ilusória e sofística e, na Idade Média, vinculada ao trabalho puramente manual. Desse modo, "na medida em que a linguagem goza precisamente, desde a Antiguidade, do privilégio de ser ao mesmo tempo a ordem do discurso e da razão" (LICHTENSTEIN, 2005, p. 12), a ligação constitutiva entre as duas artes serviu ao propósito de estabelecer que a pintura "provém da idéia, e não da matéria; do intelecto, e não da sensibilidade; da teoria, e não da prática" (LICHTENSTEIN, 2005, p. 12). A mudança, porém, alterou não apenas o estatuto da pintura, mas também impôs a esta "as categorias da poética e da retórica, como a invenção ou a disposição, concedendo-lhe a mesma finalidade que Aristóteles atribuía à poesia dramática: a de contar a história" (LICHTENSTEIN, 2005, p. 12).

No século XVII, ainda se dirá que "o pintor deve saber 'narrar com o pincel"' (LICHTENSTEIN, 2005, p. 13). Pintar, na concepção de pintura narrativa, consiste "em transpor uma sequência narrativa, e, portanto temporal, para o espaço de visibilidade que é o quadro; em descobrir os meios de representar fielmente uma história respeitando certo número de exigências próprias à composição pictórica" (LICHTENSTEIN, 2005, p. 13). Esta concepção de pintura assinalou a um só tempo o triunfo do Ut pictura poesis e da estética da imitação, e foi considerada durante séculos como "a mais alta expressão da arte de pintar", contribuindo para 
provar a "nobreza da pintura na medida em que pressupunha, tanto no pintor como no espectador, um conhecimento íntimo da literatura profana ou sagrada e da tradição interpretativa" (LICHTENSTEIN, 2005, p. 13). Nessa união entre as duas artes, os pintores tomaram seus temas da literatura, "transformando a narrativa em quadros", e os escritores celebraram os pintores em seus textos, "revelando a significação, por vezes obscuras, dessas telas" (LICHTENSTEIN, 2005, p. 13).

A respeito dessa forma de aproximar as duas artes, Mario Praz (1992, p. 13), no livro Literatura e artes visuais, originalmente Mnemosyne: the Parallel between literature and the visual arts, publicado na década de 1970, a partir da apresentação de exemplos de inter-relação entre poesia e pintura decorrentes do fato de pintores aceitarem as sugestões dos poetas (segundo o tema de "instruções ao pintor"), ou, o contrário, poetas buscarem inspiração no trabalho dos pintores (diante do grau de prestígio alcançado pela pintura na Renascença), ou de, no século XVIII, poetas e pintores idearem assuntos contemporâneos, reconheceu que "tal tipo de inter-relação pode ser largamente ilustrado por qualquer das literaturas do Ocidente, e embora constitua, legitimamente, um capítulo do estudo global do paralelo entre as artes, de modo algum é a sua parte mais importante".

A comparação entre pintura e literatura pode assumir uma forma de controvérsia envolvendo, pelos menos, duas questões: a hierarquia entre as artes e a especificidade das artes. Ainda como observou Lichtenstein (2005), dizer que a pintura é poesia muda é ocultar sua especificidade, já que a submete às artes da linguagem. Além disso, em nome da defesa da especificidade das artes, pode-se questionar a própria comparação. No século XVIII, Gotthold Ephraïm Lessing (1998, p. 211) recusou o paralelo entre as artes do visível e as do discurso, ressaltando, entre outras observações, que "a sequência temporal é o âmbito do poeta, assim como o espaço é o âmbito do artista". No entanto, para Joseph Frank (2003, p. 228), Lessing opunha-se, sobretudo, à poesia pictórica e à pintura alegórica, muito populares em seu tempo, considerando que a primeira, ao pintar com palavras, e a segunda, ao contar uma história em imagens visíveis, estavam ambas fadadas ao fracasso.

Segundo Frank, Lessing oferecia uma nova concepção da forma estética em que não sendo um arranjo externo provido por um conjunto de regras tradicionais, "é a relação entre a natureza sensorial do veículo artístico e as condições da percepção humana”. Daí, observan-
Do Ut Pictura

Poesis à narrativa de Clarice

Lispector 
Joelma Santana

Siqueira

170

do que tempo e espaço são "os dois extremos a definir os limites da literatura e das artes plásticas em sua relação com a percepção sensorial", Frank, seguindo o exemplo de Lessing, traça a evolução das formas artísticas por meio de suas oscilações entre esses dois polos na literatura moderna, demonstrando como escritores modernos espacializaram o tempo na poesia e na narrativa.

Na metade do século XVIII, a discussão sobre o tema na pintura tornou-se frequente. A esse respeito, analisando as transformações do espaço plástico do Romantismo ao Impressionismo, Pierre Francastel (1990, p. 114) observou que, no contexto do Romantismo, "os signos simbólicos sobre os quais se esteve de acordo durante gerações perderam sua clareza“; uma nova cultura e uma nova pedagogia foram elaboradas. Foi na pintura que surgiu a "primeira brecha introduzida pela evolução da sociedade e da técnica" (FRANCASTEL, 1990, p. 114), mas ela não questionou o sistema figurativo, a transformação iniciou-se pela crise do tema. Situando o começo dessa batalha do tema na metade do século XVIII, traçou brevemente seu percurso.

No primeiro momento, "o serviço de Monumentos do rei, já percebendo uma crise cujo fim, um século mais tarde, Paul de Saint-Victor irá apenas constatar, decide exigir dos pintores quadros representando 'temas históricos"' (FRANCASTEL, 1990, p. 114). Para Francastel, esse foi "um episódio da crise que produziu, mais ou menos nessa mesma época, La Henriade e o desmoronamento da tragédia clássica" (1990, p. 114). Certa linguagem intelectual se perdeu. O público, já ampliado, não falava mais “a língua de Ovídio e dos trágicos para transpor sem esforço seus sentimentos e seus julgamentos através dos mitos elaborados e interpretados durante séculos de pedagogia humanista" (FRANCASTEL, 1990, p. 114).

Depois, veio "a crise do Neoclassicismo", quando, mais do que nunca, o formulário erudito tornou-se "um jogo de espírito e deixou de ser efetivo". Posteriormente, foi a vez da "batalha entre os fazedores de alegorias românticas, os pintores da realidade e os que cultivam o ideal " ${ }^{\text {"1 }}$ (FRANCASTEL, 1990, p. 115).

1. Sobre "os pintores que cultivam o ideal", ler, por exemplo, a introdução do capítulo "Simbolismo e outras tendências subjetivas", de Herschel B. Chipp (1988, p. 45): "Os artistas que participaram dos movimentos subjetivistas de cerca de 1885-1900 podem ser agrupados apenas porque todos rejeitaram as concepções realistas da arte que havia predominado na geração anterior; estilisticamente, variavam muito. Seguindo a liderança dos poetas avançados, afastaram-se do mundo exterior para o mundo interior dos sentimentos, em busca de seus temas". 
No final do século XVIII e começo do século XIX, inicia-se a discussão sobre a crise da representação, que, como bem destacou Kerstin Behnke (1994, p. 7), tem sido frequentemente atualizada e diz respeito à experiência de que os sistemas de representação humana, particularmente a linguagem, “já não se mostram adequados à realidade e que, desta maneira, o termo representação perde, enquanto forma de conhecimento, sua garantia universal relativa à ordem das coisas". A validez da representação como modelo universal e invariável do conhecimento foi quebrada pelo desenvolvimento da consciência histórica entre 1775 e 1825, a subjetividade nascente e a historicização do saber: o vínculo entre linguagem e pensamento foi destruído "e a representação não é mais a razão oculta para a ordem das coisas" (BEHNKE, 1994, p. 13).

Simplificando, pode-se destacar que a caminho do XIX, ampliou-

Do Ut Pictura

Poesis à narrativa de Clarice

Lispector

-se cada vez mais a consciência de que se pode sempre saber mais sobre tudo, mesmo diante dos saberes todos, mas, isso, paradoxalmente, é fonte de incertezas. Behnke, citando Foucault, ressalta que

\footnotetext{
a condição de 'entreligar as representações ou, entre elas, os elementos de cada uma'está agora fora da representação, em um 'espaço interno', na profundidade invisível das próprias coisas tornadas históricas e reflexivas, as quais 'se enrolam em si mesmas'e que só fragmentariamente são acessíveis à representação: 'o ser mesmo do que é representado vai agora cair fora da própria representação (BEHNKE, 1994, p. 13).
}

Recorrendo a Lukács, Behnke observa que o romance é a forma representativa capaz de expressar o estado de espírito contemporâneo, o da "errância transcendental". o gênero anticlássico por excelência, como destacou Mikhail Bakhtin (1988), é o único nascido na era moderna e ainda por se constituir. Walter Benjamin (1987), no importante ensaio "O narrador", de 1936, identificava a perda da forma tradicional de narrar no mundo moderno com a perda da capacidade do homem de intercambiar experiências em um contexto em que a imagem do mundo exterior e do mundo ético sofreu transformações inimagináveis. 0 primeiro indício dessa perda que vem de longe foi o surgimento do romance, que encontrou na burguesia ascendente, no início do período moderno, os elementos favoráveis a seu florescimento. Nas palavras de Benjamin, "escrever um romance significa, na descrição de uma vida humana, levar o incomensurável a seus últimos limites” (1987, p. 201). 
Joelma Santana

Siqueira

172

$\mathrm{Na}$ pintura, a discussão sobre a crise do tema, como demonstrou Francastel, prosseguiu e foi por volta de 1880 que os impressionistas, "em toda uma série de obras agradáveis, nas quais se transformaram em cronistas e ilustradores de sua época", fizeram "os temas contemporâneos triunfar definitivamente, se não diante do público do momento, pelo menos diante das gerações futuras" (1990, p. 116). Sem realizar uma análise dos detalhes do conflito que, como escreveu, "lentamente, levou os artistas de um intento de rejuvenescer a pintura modernizando os temas sem modificar, por assim dizer, a morfologia de sua arte, a uma verdadeira crise da expressão", considerou que, "o romantismo deu uma grande contribuição de imagens e idéias novas, mas evitou questionar os marcos estáveis da representação plástica do espaço"; e os realistas, "em certa medida, também acreditaram que a discussão sobre o tema dominava todas as outras", porém, os que fizeram triunfar o programa de Courbert, nas palavras do autor, "os que pareciam formar a segunda geração realista",

\footnotetext{
introduziram novidades que tornaram súbito possível uma transformação tão completa das relações entre o pintor e a natureza, entre o pintor e o espectador, e que veio sortida de uma série de invenções técnicas tão revolucionárias, que se pode afirmar ter sido virada mais uma página da história das linguagens plásticas da humanidade (FRANCASTEL, 1990, p. 116-117).
}

Francastel considera que os impressionistas foram os precursores dessa mudança e, "em certo sentido, a história do último meio século é a história da descoberta pelo grande público do balanço do impressionismo" (1990, p. 192). Detendo-se na pintura de Cézanne, propôs que o objetivo do pintor é a descoberta dos fragmentos de natureza nos quais se exprime seu interesse com relação ao mundo, e nessa nova atribuição de valores a determinados aspectos de nosso ambiente há "uma definição de novos objetos simultaneamente reais e imaginários". Desse modo, ressaltando que “a maçã será inapreensível e a montanha manejável e flexível, segundo a vontade do artista" (FRANCASTEL, 1990, p. 192), entende que Cézanne não apenas evade-se do universo geográfico do Renascimento, mas também de

um universo mental no qual as funções recíprocas dos seres e das coisas são definidas. A arte renuncia à anedota e à história para tornar-se empirismo e panteísmo; ela escreve a história das 
A pintura deixou de ser pintura de história ou de ideias. Seu espaço pode ser definido como um "espaço em obra", como propôs Alberto Tassinari (2001, p. 69), explicando que nele "os sinais do fazer" se mostram muito mais do que na pintura naturalista, que ocultava suas estratégias. No espaço em obra, "a obra expõe junto com o que comunica também passos para compreendê-la" (TASSINARI, 2001, p. 69). A essa pintura, corresponderá uma narrativa que também deixa de se apresentar como uma história cujas partes se dispõem em relação causal de fá-

Do Ut Pictura

Poesis à narrativa de Clarice

Lispector cil apreensão. Nesse contexto, a aproximação entre pintura e literatura traz para o centro da questão o "ut", o "como", a comunicação entre as formas artísticas. A crítica à pintura literária ou filosófica, à pintura de história ou de ideias, a uma pintura que continua reivindicando a doutrina do Ut pictura poesis, será assunto insistente do discurso da modernidade, não totalmente ultrapassado no século XX, haja vista que, como observou Lichtenstein (2005, p. 14-5), o influente crítico de arte norte-americano Clement Greenberg, no artigo intitulado "Rumo a um mais novo Laocoonte", publicado em 1940, mostrou "que a questão da especificidade das artes estava no centro das discussões relativas à abstração".

Em outro artigo, "A crise da pintura de cavalete", de 1948, Clement Greenberg (1996) aproximou pintura e literatura a partir da observação dos procedimentos formais realizados pelos artistas modernos. Após destacar que a superfície indiferenciada na pintura, iniciada por Manet, encontrava-se na mais recente pintura, a pintura all-over, "'descentralizada', 'polifônica'que depende de uma superfície composta de elementos idênticos ou muito semelhantes que se repetem sem uma variação marcada de uma borda a outra da pintura", em outras palavras, "um tipo de pintura que prescinde, evidentemente, de princípio, meio e fim", propunha que se tratava de um aspecto que parecia "corresponder a algo profundamente enraizado na sensibilidade contemporânea" (GREENBERG, 1996, p. 165), e tinha seu paralelo na literatura de James Joyce e Gertrude Stein. Na conclusão do artigo, ressaltando que talvez a pintura all-over responda ao sentimento de que todas as distinções hierárquicas foram exauridas e invalidadas, "de que nenhuma área ou ordem de experiência é intrinsecamente 
Joelma Santana

Siqueira

174

superior, em qualquer escala de valor, a qualquer outra área ou ordem de experiência", anunciava que o futuro da pintura de cavalete tornou-se problemático, prevendo que ao usar essa convenção, artistas como Pollock estavam "a caminho de destruí-la" (GREENBERG, 1996, p. 167).

No século XX, outras questões são acrescentadas à discussão sobre a comparação entre a literatura e outras artes. 0 crítico e escritor Michel Butor (1974, p. 232), um dos novos-romancistas franceses (romancistas que logo após a Segunda Guerra Mundial foram considerados criadores de uma "nova escola" dentro do romance francês por jornalistas e críticos), no volume de ensaios intitulado Repertório, chama-nos a atenção para um aspecto que altera a comparação entre literatura e outras artes na modernidade: o de que nos encontramos "diante de tais transformações dos meios de comunicação que somos obrigados a colocar em novos termos o problema da relação da literatura com as outras artes concernentes ao ouvido ou ao olho, à música e à pintura". Como ressalta, "ouvimos muitos ruídos ao mesmo tempo, o mundo moderno é mais barulhento do que outrora, há mais gente falando e suas vozes são multiplicadas por inúmeros aparelhos; a questão da superposição das falas reveste-se, pois de uma importância cada vez maior" (BUTOR, 1974, p. 237). A percepção da imagem e do som foi alterada pelo cinema e pela televisão, que "transformaram a relação entre aquilo que vejo e o que ouço, atraindo nossa atenção para os aspectos visuais da dicção" (BUTOR, 1974, p. 239).

A importância do cinema para as outras artes foi enfatizada pelo autor da História social da arte e da literatura, Arnold Hauser (2003, p. 970), para quem o novo conceito de tempo, "cujo elemento básico é a simultaneidade e cuja natureza consiste na espacialização do elemento temporal", em nenhum gênero se expressa de maneira tão impressionante quanto "na mais jovem de todas as artes, a qual data do mesmo período que a filosofia do tempo de Bergson". Destacando a completa concordância entre os métodos técnicos do cinema e as características do novo conceito de tempo, ressaltou que "se tem a sensação de que as categorias temporais da arte moderna, como um todo, devem ter surgido no espírito de forma cinematográfica, e fica-se propenso a considerar o próprio cinema como o gênero estilisticamente mais representativo da arte contemporânea" (HAUSER, 2003, p. 970).

Sua História foi publicada em 1950. Em 1945, o crítico norte-americano Joseph Frank, no ensaio citado anteriormente, "A forma espacial na literatura moderna", analisou o modo como os escritores T.S. Eliot, Ezra Pound, Flaubert, James Joyce e Marcel Proust espacializaram o tempo em suas obras. 
Para Frank, o desaparecimento da profundidade na arte não naturalista deveria ser visto como uma observação de primeira importância para o entendimento da forma espacial na literatura moderna. A discussão sobre a figuração do tempo e do espaço na obra de arte permanece, mas, agora, com uma percepção maior de que esses dois elementos são intercambiáveis.

No que diz respeito aos aspectos metodológicos da comparação entre as artes, nos anos 1940, René Wellek e Austin Warren propuseram que a comparação da literatura com as outras artes deve priorizar a análise das relações estruturais, pois consideram que

a mais discreta forma de abordarmos a comparação das várias artes consiste, obviamente, naquela que se alicerce sobre uma análise dos próprios objectos de arte e, assim, das suas relações

Do Ut Pictura

Poesis à narrativa de Clarice

Lispector

Em direção oposta à comparação temática, propuseram a análise das homologias estruturais, para eles, mais relevantes que a pesquisa das relações histórico-sociais das obras com seus contextos.

Diferentemente de René Wellek e Austin Warren (1955, p. 169), que recusam a ideia de um "'espírito do tempo'determinando e infiltrando-se em toda e qualquer arte", Mario Praz (1982) propôs que talvez "a maneira certa de se encontrar uma base firme para os paralelos entre as diversas artes" assemelhe-se àquilo que Vladimir Propp encontrou no campo dos contos de fadas:

De igual maneira, pode-se perguntar se, sem considerar os meios em que as obras de arte são realizadas, as mesmas tendências estruturais, ou tendências similares, não estariam em ação, num determinado período, no modo por que as pessoas concebem ou veem as coisas, ou, melhor ainda, memorizam esteticamente os fatos, e se nisto não se pode eventualmente encontrar uma base para os paralelos entre as artes. Os diferen- 
tes meios de expressão corresponderiam, então, à variedade de caracteres nos contos de fadas: a proposição de que os caracteres variam, enquanto que as funções permanecem as mesmas, encontraria sua contrapartida em outra proposição: os meios variam, a estrutura permanece a mesma (PRAZ, 1982, p. 57).

Joelma Santana

Siqueira

176

Ao incluir o modo pelo qual as pessoas concebem ou veem as coisas, ou melhor, memorizam esteticamente os fatos em um determinado período, a abordagem de Mario Praz contempla, além das relações estruturais, os contextos culturais nos quais as estruturas se inserem e, a esse respeito, vale observar algumas ideias de Claus Clüver sobre a especificidade dos estudos interartes diante dos estudos culturais nas últimas décadas do século XX. Para Clüver (1997, p. 57), há dois tipos de abordagens dos estudos interartes contemporâneos, "aqueles que enfatizam os estudos de textos e de suas relações intertextuais enquanto tais e aqueles que abordam fenômenos interartes sobretudo como produtos e práticas socioculturais". Em ambos os casos, porém, como adverte, "estaremos tratando de questões relativas à produção e à recepção de textos, a autores e leitores, e por esta razão apenas será impossível excluir a dimensão dos contextos culturais" (CLÜVER 1997, p. 57).

$\mathrm{O}$ risco, para o autor, estava na possibilidade de as abordagens e os interesses dos novos estudos culturais absorverem os estudos interartes, agindo como uma superdisciplina que, como informou, nos EUA e no Reino Unido, ao longo da última década do século XX, ameaçava também engolfar os estudos literários e a literatura comparada. Seu texto é da década de 1990 e reflete a preocupação de alguns estudiosos da teoria da literatura diante do até então recente avanço dos estudos culturais $^{2}$ nas instituições de ensino. 0 autor reconhecia que os estudos interartes, determinados pelas mesmas preocupações que dominavam o discurso crítico atual, deviam frequentemente coincidir com os objetivos dos estudos culturais, porém, ressaltava que os vários textos que combinavam ou fundiam códigos semióticos diferentes requerem com-

2. Walter Moser (1998, p. 66), em artigo sobre os Estudos Literários (EL) e os Estudos Culturais (EC), propondo uma visão positiva da tensão entre ambos, esclarece: "na fase de surgimento e estabelecimento institucional dos EC, a integração pura e simples dos EL nos EC foi, de fato, sugerida muitas vezes. A formulação do título de um recente livro de Antony Easthope faz disso um programa explícito: Literary into Cultural Studies. No entanto, Easthope não é o único a propor essa relação particular, e sua formulação desse projeto está longe de ser a menos atenuada. Brantlinger segue, igualmente, a mesma linha de argumentação em apresentação dos Cultural Studies in Britain and America. Finalmente, em Eagleton, encontramos uma retórica que, tendo descoberto na teoria literária muitos defeitos e impossibilidades, acaba sugerindo a passagem dos EL aos EC". 
petência específica. Os estudos interartes, como disciplina específica, teriam como uma de suas funções a formação de leitores equipados para lidar com intertextualidade interartes.

No trabalho de comparação entre literatura e pintura a linguagem está no centro das preocupações. A esse repeito, Merleau-Ponty (2004, p. 73), no ensaio "A linguagem indireta e as vozes do silêncio", publicado originalmente em julho de 1952, na revista Les temps modernes, ao distinguir na linguagem um uso empírico e um uso criador, observou que a "palavra no sentido da linguagem empírica - isto é, a chamada oportuna de um signo preestabelecido - não o é em relação à linguagem autêntica". Nas expressões já adquiridas, "há um sentido direto, que corresponde ponto por ponto a torneios, formas, palavras instituídas. Aparentemente, não há lacuna aqui, nenhum silêncio falante" (MERLEAU-PONTY, 2004,

Do Ut Pictura

Poesis à narrativa de Clarice

Lispector p. 73). Diferentemente, o sentido das expressões que se estão realizando "é um sentido lateral ou oblíquo, que se insinua entre as palavras, é uma outra maneira de sacudir o aparelho da linguagem ou da narrativa para arrancar-lhe um som novo" (MERLEAU-PONTY, 2004, p. 75-6). O paralelo entre literatura e pintura é proposto pelo filósofo a partir deste modo de conceber a linguagem autêntica, a linguagem em sua operação de origem:

Se quisermos compreender a linguagem em sua operação de origem, teremos de fingir nunca ter falado, submetê-la a uma redução sem a qual ela nos escaparia mais uma vez, reconduzindo-nos àquilo que ela nos significa, olhá-la como os surdos olham aqueles que estão falando, comparar a arte da linguagem com as outras artes de expressão, tentar vê-la como uma dessas artes mudas. É possível que o sentido da linguagem tenha um privilégio decisivo, mas é tentando o paralelo que perceberemos aquilo que talvez o torne impossível ao final. Comecemos por compreender que há uma linguagem tácita e que a pintura fala a seu modo (MERLEAU-PONTY, 2004, p. 76).

Para que este paralelo se torne mais compreensível, é preciso observar que Merleau-Ponty, partindo do fato de que os dados do sentido variam através do século, considera que a perspectiva clássica "é uma das maneiras inventadas pelo homem de projetar à sua frente o mundo percebido, e não o seu decalque" (2004, p. 78). Mais do que um segredo técnico para imitar uma realidade que se ofereceria igualmente a todos 
Joelma Santana

Siqueira

178

os homens, a perspectiva é "a invenção de um mundo dominado, possuído de parte a parte numa síntese instantânea da qual o olhar espontâneo nos dá, quando muito, o esboço ao tentar em vão manter juntas todas essas coisas que, individualmente, querem-no por inteiro". Daí, se mesmo a pintura 'objetiva'é uma criação, o autor, discordando de Malraux, considera que não "há razões para conceber a pintura moderna, por querer ser ela criação, como uma passagem para o subjetivo, uma cerimônia em glória do indivíduo" (MERLEAU-PONTY, 2004, p. 80).

Sua compreensão da tolerância dos pintores modernos para com o inacabado relaciona-se ao modo como percebe a obra consumada: não é aquela que existe por si só como coisa, é "aquela que atinge seu espectador, convida-o a recomeçar o gesto que a criou e, pulando os intermediários, sem outro guia além do movimento da linha inventada, do traçado incorpóreo, reunir-se ao mundo silencioso do pintor, a partir daí proferido e acessível" (MERLEAU-PONTY, 2004, p. 81). Na base desta compreensão está o saber de que "a percepção nunca está acabada". Mais do que a volta ao indivíduo, ou a volta à subjetividade, Merleau-Ponty propõe que a pintura moderna coloca "o problema de saber de que modo é possível comunicar-se sem o amparo de uma Natureza preestabelecida e à qual se abriam os sentidos de todos nós, de que modo estamos entranhados no universal pelo que temos de mais pessoal" (MERLEAU-PONTY, 2004, p. 82).

Daí, correlacionar percepção, história e expressão para demonstrar porque é legítimo tratar a pintura como uma linguagem, propondo que "um romance exprime tacitamente como um quadro", e que se pode "contar o tema do romance como do quadro", mas o importante não se encontra naquilo que está dito. "O romance como relato de acontecimentos, como enunciados de ideias, teses ou conclusões, como significação manifesta ou prosaica, e o romance como operação de um estilo, significação oblíqua ou latente, encontra-se numa mera relação de homonímia" (MERLEAU-PONTY, 2004, p. 111). Para Merleau-Ponty, enquanto, na pintura, o espectador não deve contar com outro guia além do movimento da linha inventada, do traçado incorpóreo a fim de "reunir-se ao mundo silencioso do pintor, a partir daí proferido e acessível", na literatura, a condição para existir a linguagem literária está em deixarmos "as palavras e todos os meios de expressão do livro se envolverem nessa auréola de significação que devem à sua disposição singular, e o escrito inteiro vire para um valor 
secundário onde quase assume a irradiação muda da pintura" (MERLEAU-PONTY, 2004, p. 112). Em ambos os casos, enfatiza-se a necessidade de percebermos a comunicação da forma.

Os textos "Romance" e "Escrever, humilde, técnica", de Clarice Lispector, publicados em A legião estrangeira (1964), trazem reflexões sobre sua escritura e permitem-nos estabelecer relações entre sua literatura e a arte moderna. No primeiro, observa-se a consciência da escritora de que seu romance não se confunde com o romance "atraente", para o entretenimento, próximo de um tipo de pintura que Breton denominou de "dissertação ociosa acerca de um mundo de ninharias". No segundo, a partir da reflexão da autora sobre sua técnica, é possível discutir relação entre seu estilo e o estilo de certos artistas plásticos modernos.

Como observou o crítico Carlos Mendes de Sousa (2000, p. 294), Do Ut Pictura Poesis à narrativa de Clarice Lispector o texto "Romance" busca "explicações às analogias de domínio pictural - a moldura e o quadro". No pequeno texto, Lispector escreve sobre o romance atraente, que é diferente do seu romance, pois enuncia:

\footnotetext{
Ficaria mais atraente, se eu o tornasse mais atraente. Usando, por exemplo, algumas coisas que emolduram uma vida ou uma coisa ou romance ou um personagem. É perfeitamente lícito tornar atraente, só que há o perigo de um quadro se tornar quadro porque a moldura o fez quadro. Para ler, é claro, prefiro o atraente, me cansa menos, me arrasta mais, me delimita e me contorna. Para escrever, porém, tenho que prescindir. A experiência vale a pena, mesmo que seja apenas para quem escreveu (LISPECTOR, 1964, p. 139).
}

Um dos traços marcantes que ela destaca no romance atraente, além de aproximá-lo do quadro que se torna quadro apenas porque a moldura o fez quadro, é que ele "contorna quem o lê". Para discutir este aspecto, vale observar o modo como Merleau-Ponty (2004, p. 130) explicou o contorno dos objetos no texto "A dúvida de Cézanne“: o uso do contorno como procedimento que confere identidade às coisas, aprisiona-as em formas rígidas, sacrificando a profundidade, "a dimensão que nos oferece a coisa, não como exposta diante de nós, mas como cheia de reservas e como uma realidade inesgotável".

O contorno em uma obra literária pode ser observado, por exemplo, na descrição minuciosa da personagem por parte do narrador onisciente, dando ao leitor a análise de seus sentimentos e de sua aparência 
Joelma Santana

Siqueira

180

física, visando definir um "eu" como uma realidade esgotável. Não é isso que Clarice Lispector faz em suas narrativas. Como observou Benedito Nunes (1969, p. 119), "nos romances de Clarice Lispector, o Eu, reduto da personalidade, que é a exteriorização do ser psíquico, o Eu, como base da identidade pessoal dos indivíduos, cai por terra". Constantemente desfeita e refeita, "a identidade pessoal parece mais um ideal a atingir, um produto da imaginação, uma meta a alcançar, do que um dado real".

0 romance atraente, que contorna quem o lê, na descrição de Clarice Lispector, assemelha-se ao romance como mero relato de acontecimentos, ou, nas palavras de Lukács (2000, p. 73), “à caricatura do romance", descrita após destacar que apenas o romance possui uma caricatura que lhe é quase idêntica em todos os aspectos não essenciais da forma: "a leitura de entretenimento, que indica todas as características exteriores do romance, mas que em sua essência não se vincula a nada e em nada se baseia, carecendo com isso de todo o sentido".

É por oposição ao romance atraente que Clarice Lispector nos permite propor o paralelo entre seu romance e a pintura moderna. Sobre sua narrativa, podemos dizer o mesmo que Clement Greenberg observou da pintura de superfície indiferenciada: prescinde de princípio, meio e fim, e, como a pintura, parece responder ao sentimento de que as distinções hierárquicas foram exauridas e invalidadas, de que nenhuma experiência é intrinsecamente superior à outra. Daí, na obra clariciana, observarmos tantas vezes a circularidade da forma, que contribui para a ênfase dada aos instantes de vida do personagem em detrimento à ênfase em um acontecimento hierarquicamente superior.

No início do texto "Escrever, humildade, técnica", Clarice Lispector se refere a seu 'estilo', que, como informa, “já foi chamado de várias coisas, menos do que realmente e apenas é: uma procura humilde". 0 texto parece um quebra-cabeça de palavras, desarrumado e incompleto, pois começa do seguinte modo: "Essa incapacidade de atingir, de entender, é que faz com que eu, por instinto de ...de quê? Procure um modo de falar que me leve mais depressa ao entendimento". A incapacidade, longe de se reduzir a um empecilho, conduz o sujeito à procura. A autora informa que nunca teve "um só problema de expressão, meu problema é muito mais grave: é o de concepção". Sobre a palavra humildade, esclarece que a está empregando "no sentido cristão (como ideal a poder ser alcançado ou não)", "humildade que vem da plena consciência de se ser realmente incapaz", "humildade como técnica". Há uma passagem interessante que deve ser citada antes de continuarmos: 


\begin{abstract}
Virgem Maria, até eu mesma me assustei com minha falta de pudor; mas é que não é. Humildade como técnica é o seguinte: só se aproximando com humildade da coisa é que ela não escapa totalmente. Descobri este tipo de humildade, o que não deixa de ser uma forma engraçada de orgulho (LISPECTOR, 1964, p. 144. Grifo nosso).
\end{abstract}

Observa-se que apenas se aproximando humildemente da coisa ela não escapa totalmente, arriscamos um entendimento para a técnica da escritora: um método de escrever que integra ao momento do trabalho artístico o instante do ato perceptivo. A técnica, conjunto de conhecimentos de aplicação prática, descrita como humildade e para uso de um sujeito do fazer que se sabe "realmente incapaz", é uma técnica diferente ("é que não é"): por meio dela, a escritora põe em prática a aproximação aos poucos e obtém expressões acabadas da percepção inacabada.

Esta técnica assemelha-se à do pintor Francis Bacon, que também enfatiza a importância do instante em que o objeto é percebido, considera que a técnica e o objeto se confundem e entende que a arte reside na luta do artista para se aproximar do lado sensorial dos objetos. Igualmente, esta técnica assemelha-se ao modo como o crítico de arte Rodrigo Naves (1996, p. 183) percebe o esforço formalizador de Alfredo Volpi ao considerar que o pintor "persegue uma espécie de sabedoria em ato, em que inexiste separação ou precedência entre teoria e prática, pois ambos são momentos de uma mesma atividade reflexionante, avessa ao dualismo sujeito-objeto".

Alberto Tassinari (2004, p. 145), no esboço de leitura para o texto "A dúvida de Cézanne", citado anteriormente, observou que, na principal obra de Merleau-Ponty, Fenomenologia da percepção, “a percepção é compreendida como um 'acesso à verdade'. A verdade, entretanto, não nos dá nunca o acabado. Uma verdade acabada seria a paralisia do presente, a situação em que me encontro, tanto fonte de meus acertos quando de meus erros". Ao Consider-se que o inacabado da percepção permite a junção de alguns temas das duas obras de Merleau-Ponty, Tassinari observou que os dois textos, ao final, falam da liberdade. "E a liberdade, como a verdade, também nunca está pronta". Sendo assim, reflete-se que: se é uma liberdade a busca de Cézanne, “o que há de incompletude e insatisfação nessa realização já não será só falha ou dúvida, mas também certeza de que
Do Ut Pictura

Poesis à narrativa de Clarice

Lispector 
Joelma Santana

Siqueira

182

aquilo que nos aparece ao mesmo tempo nos escapa". Em relação ao texto clariciano, pode-se pensar que a "forma engraçada de orgulho" talvez decorra de uma certeza semelhante.

O estilo moderno parece resultar desta espécie de consciência da humildade que é, a um só tempo, dúvida e certeza. Esta consciência da impossibilidade de fixar a transitoriedade das coisas foi observada por Leyla Perrone-Moisés (1966, p. 20) em relação aos "novos-romancistas" ao destacar que eles entendem o campo do romance como o campo dos possíveis, ressaltando que, "no campo da expressão, o reconhecimento das várias camadas do real e das possibilidades infinitas do tempo romanesco leva-os a uma atitude de humildade quanto à possibilidade de conhecer e de exprimir". A perda do modo tradicional de narrar, relacionado ao modo como o homem moderno experimenta o mundo, leva a outras formas artísticas que se caracterizam de modo especial por trazer a linguagem (na literatura e na pintura) para o primeiro plano da obra.

Erich Auerbach (2004), ao realizar o estudo da mimesis na literatura ocidental, em trabalho publicado originalmente em 1946, no capítulo dedicado à narrativa de Virginia Woolf, observou que muitas formas estilísticas (erlebte Rede, stream of consciousness ou monologue intérieur) empregadas pelos escritores para reproduzir o conteúdo da consciência das personagens foram empregadas muito antes na literatura, mas ressaltou a diferença na intenção artística moderna. Ele observa que o escritor moderno coloca a si próprio como quem duvida, "interroga e procura, como se a verdade acerca da sua personagem não lhe fosse mais bem conhecida do que às suas próprias personagens ou ao leitor", e propõe que o que está em questão é "a posição do escritor diante da realidade do mundo que representa", diferente da posição dos escritores que partiam de um conhecimento seguro sobre os personagens e suas histórias (AUERBACH, 2004, p. 482).

A narrativa deixa de ser a história de uma personagem, de um acontecimento etc., para ser a história da escritura, exigindo do leitor um olhar que veja além da representação. Ela requer ainda mais do leitor uma percepção da forma artística que não se confunda com a percepção da realidade vivida. A esse respeito, Ortega y Gasset (2005, p. 47), observando que a percepção da forma artística requer acomodação diferente em nosso aparelho receptor, sobre a nova inspiração dos artistas modernos, considerou que o artista moderno 
voltou a tocar no "caminho real da arte", a "vontade de estilo", que implica na "desumanização da arte", no sentido de que estilizar é desumanizar. A concepção de desumanização na arte se torna mais clara, porém, quando Ortega considera que a propensão humana é fruto de nossa tendência natural de esquecer que há sempre uma absoluta distância entre a ideia e a coisa, confundindo a realidade com a ideia, "tomando esta de boa-fé pela própria coisa". A propensão nativa humana diz respeito ao fato de que "nosso prurido vital de realismo nos faz cair numa ingênua idealização do real" (ORTEGA, 2005 , p. 64). A arte moderna elimina ou problematiza o engodo da ilusão, que passa a ser vista como prejudicial, a exemplo do que se pode notar nas palavras de Michel Butor (1974, p. 11-12) ao ressaltar que "a busca de novas formas romanescas cujo poder de integração

Do Ut Pictura

Poesis à narrativa de Clarice

Lispector seja maior representa, pois, um triplo papel com relação à consciência que temos do real: de denúncia, de exploração e de adaptação". Sobre os romancistas que recusaram este trabalho, ressaltou que podem obter êxito mais facilmente, mas, "torna ainda mais rígidos os reflexos da consciência, mais difícil seu despertar, contribui para a sua asfixia, tanto que, mesmo se ele tiver intenções generosas, sua obra é finalmente um veneno" (BUTOR, 1974, p. 12).

Além da dúvida sobre a matéria narrada que os narradores explicitam, outro modo de transtornar os hábitos dos leitores está na quebra da sucessão temporal. Nesse sentido, Auerbach (2004, p. 497) observou que a narrativa de Virginia Woolf, ao "enfatizar o acontecimento qualquer, não aproveitá-lo a serviço de um contexto planejado da ação, mas em si mesmo", tornou "visível algo de totalmente novo e elementar: precisamente, a pletora de realidade e profundidade vital de qualquer instante ao qual nos entregamos sem preconceito". Não são os grandes momentos que contam, apenas, mas os instantes de que é feito o tempo continuamente, mesmo quando imperceptível.

A leitura dos dois textos de Clarice Lispector possibilita-nos estabelecer um diálogo entre sua narrativa e aspectos importantes da arte moderna, permitindo-nos, também, observar a consciência da escritora sobre a forma artística da arte moderna e seu estilo reflexionante. 


\section{REFERÊNCIAS BIBLIOGRÁFICAS}

AUERBACH, Erich. Mimesis - a representação da realidade na literatura ocidental. São Paulo: Perspectiva, 1971.

BAKHTIN, Mikhail. Questões de literatura e de estética: a teoria do romance. Trad. Aurora Fornoni Bernardini. et al. $4^{\mathrm{a}}$ ed. São Paulo: Editora UNESP, 1998.

Joelma Santana Siqueira
BEHNKE, Kerstin. “A crise da representação”. Cadernos do mestrado/literatura. n. 10, Rio de Janeiro: UERJ, 1994.

BENJAMIN, Walter. "O narrador. Considerações sobre a obra de Nikolai Leskov". In: Obras escolhidas. Magia e técnica, arte e política. Vol. 1. São Paulo: Brasiliense, 1987.

BUTOR, Michel. Repertório. Trad. Leyla Perrone-Moisés. São Paulo: Perspectiva, 1974.

CHIPP, Herschel Browning. Teorias da arte moderna. Trad. Waltensir Dutra et al. São Paulo: Martins Fontes, 1988.

CLÜVER, Claus. "Estudos interartes: conceitos, teorias, objetivos". Literatura e sociedade, n. 2. São Paulo: Edusp, 1997.

FRANCASTEL, Pierre. Pintura e sociedade. Trad. Elcio Fernandes. São Paulo: Martins Fontes, 1990.

FRANK, Joseph. “A forma espacial na literatura moderna”. Revista USP, n. 58. São Paulo, 2003.

GREENBERG, Clement. Arte e cultura: ensaios críticos. Trad. Otacílio Nunes. São Paulo: Ática, 1996.

HAUSER, Arnold. História social da literatura e da arte. Trad. Álvaro Cabral. São Paulo: Martins Fontes, 2003. 
LESSING, Gotthold Ephraim. Laocoonte ou sobre as fronteiras da pintura e da poesia. Introdução, tradução e notas Márcio Seligmann-Silva. São Paulo: Iluminuras, 1998.

LICHTENSTEIN, Jacqueline. "O paralelo das artes". In: A pintura. Vol. 7. Trad. Magnólia Costa. São Paulo: Editora 34, 2005.

LISPECTOR, Clarice. A legião estrangeira. Rio de Janeiro: Editora do Autor, 1964.

Do Ut Pictura

Poesis à narrativa de Clarice

LUKÁCS, Georg. Teoria do romance. Trad. José Marcos Mariani de Macedo. São Paulo: Editora 34, 2000.

MERLEAU-PONTY, Maurice. o espírito e o olho: seguido de A linguagem indireta eas vozes do silêncio e A dúvida de Cézanne. Trad. Paulo Neves e Maria Ermantina Galvão Gomes. São Paulo: Cosac Naify, 2004.

MOSER, Walter. "Estudos literários". Literatura e sociedade, n. 3. São Paulo: Edusp, 1998.

NAVES, Rodrigo. A forma difícil: ensaios sobre a arte brasileira. São Paulo: Ática, 1996.

NUNES, Benedito. o dorso do tigre. São Paulo: Perspectiva, 1969.

ORTEGA y GASSET, José. A desumanização da arte. Trad. Ricardo Araújo. 5 ed. São Paulo: Cortez, 2005.

PERRONE-MOISÉS, Leyla. O novo romance francês. São Paulo: Buriti, 1966.

PRAZ, Mário. Literatura e artes visuais. Trad. José Paulo Paes. São Paulo: Cultrix, 1982.

SOUSA, Carlos Mendes. Clarice Lispector: figura da escrita. Braga: Universidade do Minho, Centro de Estudos Humanísticos, 2000. (Coleção Poliedro).
Lispector 
TASSINARI, Alberto. 0 espaço moderno. São Paulo: Cosac Naify, 2001. . "Quatro esboços de leitura". In: MERLEAU-PONTY, Maurice. o Olho e o espírito. Trad. Paulo Neves e Maria Ermantina Galvão Gomes. São Paulo: Cosac Naify, 2004.

WELLEK, René, WARREN, Austin. "Literatura e outras artes". In: Teoria da literatura. Trad. José Palla e Carmo. Lisboa: Europa-América, 1971.

Joelma Santana

Siqueira

Recebido em 03 de agosto de 2015 Aceito em 10 de outubro de 2015

186 